\title{
Comparative embryotoxicity and genotoxicity of the herbicide diuron and its metabolites in early life stages of Crassostrea gigas: implication of reactive oxygen species production
}

\author{
Behrens Daphne ${ }^{1}$, Rouxel Julien ${ }^{1}$, Burgeot Thierry ${ }^{1}$, Akcha Farida ${ }^{1,{ }^{*}}$ \\ ${ }^{1}$ Ifremer, Laboratoire d'Ecotoxicologie, Rue de l'lle d'Yeu, BP21105, 44311 Nantes, cedex 03, France \\ * Corresponding author : Farida Akcha, email address : fakcha@ifremer.fr
}

\begin{abstract}
:
Herbicides are one of the major classes of pollutants contaminating coastal waters over the world. Among them, diuron (3-(3,4-dichlorophenyl)-1,1-dimethylurea) is a phenylurea herbicide frequently detected in oyster-producing area, known to be toxic for this important exploited non-target species. With the aim to investigate the mechanisms by which diuron displays its toxicity in oyster, the implication of both biotransformation and oxygen reactive species (ROS) production was studied considering embryotoxicity and genotoxicity as endpoints. Comparative embryotoxicity and genotoxicity of diuron and its main metabolites (DCPMU, DCPU and 3,4-DCA) were thus studied on oyster larvae by the embryo-larval bioassay on $D$ larvae and the comet assay on trochophore larvae, respectively. Exposures were also performed in presence and absence of known ROS scavenger compounds ascorbic acid and $\mathrm{N}$-acetylcysteine, to evaluate the involvement of oxyradicals in the toxic responses. In the case of diuron, the production of ROS on exposed oyster larvae was also measured using 2',7'dichlorodihydrofluorescein diacetate as a probe for flow cytometric analysis.
\end{abstract}

The results we obtained showed the embryotoxicity and genotoxicity of diuron and its metabolites in early life stages of the Pacific oyster. For concentrations ranging from 0.05 to $0.5 \mu \mathrm{g} . \mathrm{L}-1$, diuron appeared significantly more embryotoxic than DCPMU and DCPU $(p<0.001)$. Embryotoxicity decreased with diuron metabolism as follows: diuron $\geq$ DCPMU $=$ DCPU, highlighting that biotransformation can constitute a true detoxication pathways in oyster larvae by decreasing the toxicity of the parent compound. In the opposite, no difference was observed between diuron and its metabolites concerning larval development when considering a lower and more environmentally realistic range of concentrations $(0.002$ to $0.050 \mu \mathrm{g} . \mathrm{L}-1)$. 3,4-DCA was the only compound that did not show any sign of embryotoxicity, even at concentrations up to $5 \mu \mathrm{g} \cdot \mathrm{L}-1$. Concerning genotoxicity, no significant difference was observed between diuron and all of its metabolites including 3, 4 DCA with damages detected from the concentration of $0.05 \mu \mathrm{g} . \mathrm{L}-1$. As for diuron, the toxicity of the metabolites seems to be mediated in some part by ROS production as clearly demonstrated by the decrease in genotoxicity and developmental abnormalities in the presence of the oxidant scavenger, ascorbic acid. 


\section{Highlights}

- The embryo and genotoxicity of diuron and its metabolites were compared in oyster at environmental concentrations. Biotransformation appeared as a detoxication process by decreasing the embryotoxicity of the herbicide. The involvement of ROS in both toxic endpoints was demonstrated by co-exposure with known antioxidants. Herbicide pollution is of environmental concern for its potential effect on oyster recruitment rate.

Keywords : oyster, herbicide, embryotoxicity, genotoxicity, oxidative stress, biotransformation 


\section{Introduction}

The Japanese oyster Crassostrea gigas is one of the world's leading aquaculture species. It is of particular economical importance in France since the country is the third producer of this mollusc worldwide and the first one in Europe (CNC 2013). Since 2008, 40 to 100\% of the juvenile oysters (spat) die during recurrent summer mortality events that seem to be due to a combination of different biotic (pathogens and health condition of the oysters) and abiotic (water temperature, salinity, coastal pollution and aquaculture practices) factors (Samain et al. 2007). Moreover, early life stages (eggs, embryos and larvae) of fish and aquatic invertebrates have been shown to be particularly sensitive to environmental stressors (Hutchinson et al. 1998; Mohammed 2013). This is the reason why embryolarval bioassays are widely used in ecotoxicology especially in cupped oyster, a sentinel species for the biomonitoring of the marine environment (Quiniou et al. 2007; Vethaak et al. 2015). In parallel, France is the first European user of agro-chemical products and the third one in the world with about 60,000 tons used per year (Jacquet et al. 2011). This high consumption of chemically active substances threatens coastal species through several processes such as direct or indirect run-off from agricultural areas, leakage of antifouling paints from boating activities or even accidental spills in waters (Renault 2011). Certain pesticides can so trigger toxic effects to non-target species such as bivalves and among them, oysters. Therefore among the 45 priority pollutants identified by the European Water Framework Directive, 25 are pesticides (Directive 2013/39/UE).

The herbicide diuron or DCMU (3-(3,4-dichlorophenyl) -1,1-methylurea) belongs to the phenylurea family and was widely used for both weed control in agriculture and as a bioactive substance in antifouling paints (Moncada 2004). In weeds and plants, diuron blocks the photosynthetic electron flow by competing with the plastoquinone for its receptor, which leads to a non-photochemical quenching and deleterious production of reactive oxygen species (ROS) (Geoffroy et al. 2002; Ihlaseh et al. 2011). Diuron is prohibited in France since 2008 as a phytosanitary substance and as a biocide since 2009 (Directive 2008/91/EC). Its use is also strongly regulated all around the European Union that sets up a threshold limit of $0.2 \mu \mathrm{g} . \mathrm{L}^{-1}$ for marine coastal waters. However, it remains widely used in numerous regions of the world (Lourencetti et al. 2008; Ngigi et al. 2011; King et al., 2013). Diuron is detected in coastal waters at concentrations ranging from 0.02 to $1.9 \mu \mathrm{g} . \mathrm{L}^{-1}$ (Buisson et al. 2008; Caquet et al. 2013; Loos et al. 2013). 
Once released in the environment, diuron undergoes both biotic and abiotic transformation. In soil and water, it is mainly biotransformed by fungi, bacterial communities and epiphilic biofilms into three main known metabolites (Pätzold \& Brümmer 2003; Sørensen et al. 2003; Giacomazzi \& Cochet 2004). DCPMU (3-(3,4Dichlorophenyl)-1- Methylurea) is formed after a first demethylation step and turns into DCPU (1-(3,4-Dichlorophenyl) Urea) after a second consecutive one. DCPU is finally hydrolysed into 3,4-DCA (3,4-Dichloroaniline). Diuron is also slightly photolysed and hydrolysed (Stasinakis et al. 2009; Salvestrini 2013; Zeng \& Arnold 2013). However, In a laboratory study performed in $15^{\circ} \mathrm{C}$ filtered seawater, Thomas et al. (2002) did not observe any abiotic degradation of diuron over 42 days. Therefore, diuron is considered as a rather persistent substance. DCPMU and DCPU show a lower persistence in water while 3,4-DCA presents a stronger stability (Thomas et al. 2002).

When absorbed by non-target animal species, diuron can be metabolized. In an in vitro study using microsomal incubation, Abass et al. (2007) demonstrated that human, rat, mouse, dog, monkey, minipig and rabbit have the ability to metabolise diuron into DCPMU, DCPU or 3,4-DCA depending on the species. In oyster, the low bioconcentration factor (BCF) of diuron (between 7 and 17) highlights a low ability of oyster to bioaccumulate diuron, probably due to biotransformation activities (Buisson et al. 2008; Luna-Acosta et al. 2012) that could be directly involved in the expression of its toxicity. Genotoxicity on gamete and somatic cells (Bouilly et al. 2007; Akcha et al. 2012; Barranger et al. 2014), embryotoxicity (Akcha et al. 2012; Barranger et al. 2014) and immunotoxicity (Gagnaire et al. 2007; Luna-Acosta et al. 2012; Barranger et al. 2015) were already reported after exposure to 0.05 to $3.00 \mu \mathrm{g} . \mathrm{L}^{-1}$ of diuron depending on the studies. As already demonstrated for other herbicides such as paraquat, glyphosate and atrazine, ROS production could also be involved in the toxicity of diuron (Glusczak et al. 2006; Awadalla 2012; Blahová et al. 2013; Griboff et al. 2014).

In this study, we aim to investigate the mechanisms by which diuron exerts its toxic effects on oyster. To check for a role for biotransformation, we studied the toxicity of diuron and each of its known metabolites (DCPMU, DCPU and 3,4-DCA). We first compared the potential embryo- and genotoxicity of diuron and its metabolites using the standardized embryo-larval bioassay and the comet assay respectively. To state on the possible involvement of ROS production on the measured toxic endpoints we (1) used flow 
cytometry to measure the effect of diuron exposure on ROS production and (2) studied the effect of a co-exposure of the herbicide or its individual metabolites with a know antioxidant compound on the toxic responses.

\section{Material and methods}

\subsection{Reagents}

Diuron (Pestanal, analytical standard), dimethyl sulfoxide (DMSO), normal and low melting point agarose, triton X-100, GelRed, RPMI 1640 medium, foetal bovine serum (SVF), trypsine, ascorbic acid and $N$-acetylcysteine were purchased from Sigma Aldrich Chemicals (France). DCPMU (3-(3,4-Dichlorophenyl)-1- Methylurea), DCPU (1-(3,4Dichlorophenyl) Urea) and 3,4-DCA (3,4-Dichloroaniline) (fig. 1) were purchased from Dr Ehrenstorfer (Augsburg, Germany). 2',7'-dichlorodihydrofluorescein diacetate ( $\mathrm{H}_{2} \mathrm{DCF}-$ DA) was purchased from Molecular Probes (Eugene, OR, USA). Stock solutions of, respectively, diuron, DCPMU, DCPU and 3,4-DCA at $1 \mathrm{mg} . \mathrm{L}^{-1}$ were prepared in DMSO and stored at $-20^{\circ} \mathrm{C}$. Working solutions were then prepared through successive dilutions of the stock solutions in DMSO and stored at $-20^{\circ} \mathrm{C}$.

\subsection{Genitor origin}

Sexed mature oysters (Crassostrea gigas, Thunberg, 1793) came from the commercial hatchery Guernsey Sea Farm (UK). After reception, oysters were stored at $4^{\circ} \mathrm{C}$ in filtered seawater (FSW) with aeration and used within the next two days.

The seawater used for these experiments came from the experimental hatchery of Ifremer La Tremblade (France). Water was pumped directly from the Seudre river estuary, filtered through a sand filter $(40 \mu \mathrm{m})$ and passed through UV rays. The water was stored at $4^{\circ} \mathrm{C}$ and filtered once more at $0.22 \mu \mathrm{m}$ right before use.

\subsection{Gamete recovery and fertilization}

For each assay, the gametes from two to five couples were used to reduce individual variations among genitors. For the embryotoxicity assay, mature males and females were induced to spawn by thermal shock. Oysters were transferred from $4^{\circ} \mathrm{C}$ to $15^{\circ} \mathrm{C}$ seawater 
baths for $90 \mathrm{~min}$, then transferred into a $29^{\circ} \mathrm{C}$ bath for $30 \mathrm{~min}$ to induce gamete release. Spawning individuals were then isolated in individual beakers.

For both the genotoxicity and flow cytometry analysis, spawning was induced by scarification of the gonads using a surgical scalpel for practical experimental convenience. In both cases, oocytes and spermatozoa from each individual were sieved under 100 and $40 \mu \mathrm{m}$, respectively. Sperm mobility and egg shape were observed under an inverted microscope and concentrations were determined using a Thoma cell counting chamber. Gametes from each sex were then pooled and fertilization was performed by mixing spermatozoa and oocytes in a 6:1 ratio. Within 30 min after mixing, fertilization success was checked under an inverted microscope. Fertilized eggs were then used for both embryotoxicity and genotoxicity assessment as described below.

\subsection{Embryotoxicity assay}

The embryotoxic effects of diuron, DCPU, DCPMU and 3,4-DCA were studied using the standardized embryo-larval bioassay (AFNOR XP-T-90-382). Fertilized eggs were transferred into both control and assay beakers $(30 \mathrm{~mL})$ in a final concentration of 30000 eggs/L and incubated for $24 \mathrm{~h}$ at $24^{\circ} \mathrm{C}$ in the dark to reach the developmental stage of Dlarvae.

\subsubsection{Chemical exposure}

In a first set of experiments, diuron and its metabolites were individually tested in parallel at different concentrations including environmentally relevant ones (Table 1). Control conditions were filtrated seawater (FSW) and solvent DMSO at a standardized final concentration of $0.05 \%$ in all the experiments. Regarding the results, a second set of experiments was then carried out to better characterize the lowest effective concentration inducing developmental toxicity in oyster (Table 1). It is noteworthy that 3,4-DCA was withdrawn from further analyses due to its lack of toxicity even at the highest tested concentrations during the first set of experiments. For each control (FSW, DMSO) and assay condition, three technical replicates were made and each independent experiment was repeated three times. For each embryotoxicity test, exposure to the model embryotoxicant copper sulphate (10 to $100 \mu \mathrm{g} / \mathrm{L})$ was also systematically done in parallel in order to check for the responsiveness of the bioassay as mentioned in the AFNOR procedure. 
To assess the involvement of ROS in embryotoxicity, diuron, DCPMU and DCPU were also individually tested at a concentration of $0.5 \mu \mathrm{g} \cdot \mathrm{L}^{-1}$ in the presence of two known antioxidant compounds namely $N$-acetylcysteine and ascorbic acid at different concentrations (1-300 $\mu \mathrm{M})$. Incubations were also done with the antioxidant alone in order to check for its potential impact on the toxicity of diuron and its metabolites. Because both ROS scavengers showed similar pattern of toxicity and antioxidant potential, only co-exposure with ascorbic acid was repeated twice.

\subsubsection{Analysis of D-larvae}

24hpf D-larvae were fixed with $8 \%$ neutralized formol $(0.5 \mathrm{~mL} / 30 \mathrm{~mL})$. One hundred larvae per beaker were analysed afterwards under an inverted microscope (x20) to determine the proportion of abnormal larvae, i.e. those presenting shell and/or mantle deformities.

\subsection{Genotoxicity assessment by the alkaline Comet Assay}

Genotoxic effects of diuron and its metabolites were assessed using the alkaline comet assay on $6 \mathrm{hpf}$-trochophore stage larvae using a protocol adapted from Wessel et al. (2007). Fertilized eggs were transferred into both control and assay beakers (2 L) at a final concentration of 50000 eggs/L and incubated for $6 \mathrm{~h}$ at $24^{\circ} \mathrm{C}$ in the dark to reach the stage of trochophore larvae.

\subsubsection{Chemical exposure for the genotoxicity study}

Fertilized eggs were exposed in triplicate to three concentrations of diuron, DCPMU, DCPU and 3,4-DCA (0.002; 0.05 and $\left.0.5 \mu \mathrm{g} . \mathrm{L}^{-1}\right)$. Control conditions were filtrated seawater (FSW) and solvent DMSO at a standardized final concentration of $0.05 \%$. In the case of diuron, an additional experiment was conducted by co-exposure of the fertilized eggs to a concentration of $0.5 \mu \mathrm{g} . \mathrm{L}^{-1}$ in the presence and absence of ascorbic acid (50 $\left.\mu \mathrm{M}\right)$. As for the embryotoxicity test, three technical replicates were made for both control and assay conditions and each experiment was repeated twice. Based on our experience the basal level of DNA damage (Tail DNA) in the control group was expected to be less than $18 \%$ to validate the assay.

2.5.2. Dissociation of trochophore larvae before the comet assay 
Following exposure, the 6hpf trochophore larvae from both control and assay beakers were collected on a $25 \mu \mathrm{m}$ sieve with FSW. After a gentle centrifugation for $5 \mathrm{~min}$ at 2500 rpm, larvae were re-suspended in $2 \mathrm{~mL}$ of Calcium Magnesium Free Saline buffer (CMFS) (20 mM HEPES, $500 \mathrm{mM} \mathrm{NaCl}, 12.5 \mathrm{mM} \mathrm{KCl}, 5 \mathrm{mM}$ EDTA) supplemented with $50 \%$ of 25\% trypsin-EDTA. Following gentle agitation at room temperature for $5 \mathrm{~min}$, the cell suspension was sieved through $37 \mu \mathrm{m}$ and the cells were re-suspended in CMFS supplemented with 35\% RPMI 1640 and 15\% SVF. After centrifugation (2500 rpm x 5 min), supernatant was discarded and cell pellet directly used for the comet assay.

\subsubsection{Comet assay}

For each triplicate sample, the cell pellet was re-suspended in $100 \mu \mathrm{L}$ of $0.5 \%$ low-melting point agarose (LMP) in Phosphate Buffered Saline (PBS) $137 \mathrm{mM} \mathrm{NaCl}, 2.7 \mathrm{mM} \mathrm{KCl}, \mathrm{pH}$ 7.4). Ninety $\mu \mathrm{L}$ of the suspension were pipetted over a slide previously coated with $0.5 \%$ normal melting point agarose (NMP) in PBS and spread using a micro-cover glass. Slides were immediately put on a cold tray in the dark for a couple of minutes in order to allow agarose to polymerize. Cover slides were removed and a third layer of LMP was added to the slides. Once agarose polymerized, slides were immersed in ice-cold lysis buffer $(2.5 \mathrm{M}$ $\mathrm{NaCl}, 0.1 \mathrm{M}$ EDTA-Na2, 0.01M Tris base, 1\% N-sarcosinate, 10\% DMSO, 1\% Triton X-100, $\mathrm{pH} 10$ ) and left in the dark at room temperature for an hour. At the end of the lysis period, electrophoresis for $15 \mathrm{~min}$ at $23 \mathrm{~V}(390 \mathrm{~mA}, \mathrm{E}=0.66 \mathrm{~V} / \mathrm{cm})$ was done to cause DNA migration. After the electrophoresis, slides were washed in Tris base (0.4 M, pH 7.5) and fixed in a final bath of absolute ethanol for $10 \mathrm{~min}$. Slides were left drying overnight in the dark at room temperature. Right before the analysis, slides were marked with $75 \mu \mathrm{L}$ of GelRed at $8 \mathrm{mg} . \mathrm{L}^{-1}$. After at least an hour of incubation in the dark at $4^{\circ} \mathrm{C}$, slides were observed under an optical fluorescence microscope (Olympus BX60, ×40) equipped with a CCD camera (Luca-S, Andor Technology) and an image analysis system (Komet 6, Kinetic Imaging Ltd.). Fifty nuclei were analysed per slide and the percentage of DNA present in the Comet tail (\% Tail DNA) was measured for each observed nucleus.

\subsection{ROS production measurement}

\subsubsection{The probe}


To measure the potential of diuron exposure to induce ROS production, the fluorescent probe 2',7'-dichlorodihydrofluorescein diacetate ( $\mathrm{H}_{2}$ DCF-DA) was used. This non-polar dye is regularly used in single cell analyses of oxidative stress. The molecule enters the cells where it is cleaved by esterases first into the non-fluorescent 2',7'dichlorodihydrofluorescein $\left(\mathrm{H}_{2} \mathrm{DCF}\right)$, which is converted into the highly fluorescent 2',7'dichlorofluorescein (DCF) by ROS. The intensity of the fluorescent signal is thusROS concentration-dependent. A stock solution of $\mathrm{H}_{2}$ DCF-DA at $10 \mathrm{mM}$ in DMSO was used to prepare a $625 \mu \mathrm{M}$ working solution in PBS. Both solutions were stored at $-20^{\circ} \mathrm{C}$ prior use. The ability of $\mathrm{H}_{2}$ DCF-DA to be absorbed and converted into fluorescent DCF in whole oyster trochophore larvae was previously checked by incubating oyster larvae with two different concentrations of $\mathrm{H}_{2}$ DCF-DA (50 and $138 \mu \mathrm{M}$ ) for 10, 20, 25 and $40 \mathrm{~min}$. Trochophore larvae were then observed using an optical fluorescence microscope (Olympus BX60, ×40) equipped with a CCD camera (Luca-S, Andor Technology).

\subsubsection{Chemical exposure}

Fertilized eggs were transferred into both control and assay beakers (2L, triplicate) at a final concentration of 50000 eggs/L. Diuron was tested at three concentrations $(0.002$, 0.05 and $0.5 \mu \mathrm{g} . \mathrm{L}^{-1}$ ), and $\mathrm{H}_{2} \mathrm{O}_{2}$ at $50 \mu \mathrm{M}$ was used in parallel as a positive control. For the highest concentration of diuron, a co-exposure with ascorbic acid at a final concentration of $25 \mu \mathrm{M}$ was also carried out. Following incubation for $6 \mathrm{~h}$ at $24^{\circ} \mathrm{C}$ at these different conditions, the resulting trochophore larvae were collected by sieving at $25 \mu \mathrm{m}$ in a final volume of $300 \mu \mathrm{L}$ FSW. Right before flow cytometry analyses, a positive control was prepared by exposing FSW control trochophore larvae to $50 \mu \mathrm{M} \mathrm{H}_{2} \mathrm{O}_{2}$ for $10 \mathrm{~min}$. Three independent experiments using different genitor lots were done.

\subsubsection{Flow cytometric analysis}

$\mathrm{H}_{2}$ DCF-DA was added to each sample of $300 \mu \mathrm{L}$ of trochophore larvae suspension to reach a final concentration of $50 \mu \mathrm{M}(0.05 \%$ DMSO) followed by 20 min of incubation in the dark at room temperature before analysis. ROS production measurement was carried out on a BD Fortessa X20 using an argon filter 530/30 and a blue laser at 488nm. Viability of the cells was checked by a co-incubation with DAPI at a final concentration of $1 \mu \mathrm{g} \cdot \mathrm{mL}^{-1}$. Data analysis was performed on a BD FACSDiva Software. 


\subsection{Statistical analysis}

Statistical analysis was conducted using STATISTICA version 10 (Statsoft, Inc., OK, USA). Normality was checked using Lilliefor's test and variance homogeneity by Bartlett's test. Raw data were first individually analysed for each tested toxicant (diuron and its metabolites) by main effect ANOVAs using the "independent experiment" and the "exposure modality" (controls and tested concentrations) as factors, considering the possible interaction between factors. In a second step and with the aim to compare the toxicity of diuron and its metabolites, another main effect ANOVA was also conducted with all the data using the "independent experiment", the "tested substance" and the "exposure modality" as factors, considering the possible interaction ("tested substance" $\mathrm{x}$ "exposure modality"). Tukey post-hoc test was used to analyse significant differences (p $<0.05)$.

\section{Results}

\subsection{Comparison of the toxicity of diuron and its metabolites}

\subsubsection{Embryotoxicity on oyster D larvae}

3,4-DCA was the only compound that did not show any sign of embryotoxicity during the present study, even at concentrations up to $5 \mu \mathrm{g} . \mathrm{L}^{-1}$ (data not shown). For diuron, DCPMU and DCPU, an embryotoxic effect was recorded on oyster D larvae in different extent (Fig. $2 \mathrm{~A}$ and Fig 2B).

In the case of diuron, a significant embryotoxic effect was detected from the lowest tested concentration of $0.05 \mu \mathrm{g} . \mathrm{L}^{-1}$ compared to both solvent and seawater controls ( $\left.\mathrm{p}<0.001\right)$ (Fig. 2B). The toxicity of diuron for larval development was confirmed at the same concentration by the second set of experiments with $38.2 \pm 4.5 \%$ abnormal D-larvae compared to $16.3 \pm 2.9 \%$ for the solvent control (Fig. 2A). A significantly higher level of abnormalities was measured even at the lower concentration of $0.01 \mu \mathrm{g} . \mathrm{L}^{-1}$ diuron, but only in comparison to the FSW control ( $p=0.03$ ) (Fig. 2A). 
For DCPMU, embryotoxicity was observed starting from exposure to $0.01 \mu \mathrm{g} \cdot \mathrm{L}^{-1}(\mathrm{p}=0.04)$ but with no concentration-depend increase in the \% of abnormal larvae: $29.3 \pm 1.2 \%$ abnormal D-larvae in comparison to $16.3 \pm 2.9 \%$ for the DMSO control (Fig. 2A and 2B). DCPU exposure was also associated with an increase in larval abnormalities from the concentration of $0.05 \mu \mathrm{g} \cdot \mathrm{L}^{-1}(\mathrm{p}=0.05)$. As in the case of diuron, a higher level of abnormalities was also detected at $0.01 \mu \mathrm{g} \cdot \mathrm{L}^{-1}$ but only in comparison to FSW control. (Fig. $2 \mathrm{~A}$ and $2 \mathrm{~B})$.

By using all the data available from this study, we directly compared the embryotoxicity of diuron and its DCPMU and DCPU metabolites for each set of experiments. When testing concentrations ranged from 0.05 to $0.50 \mu \mathrm{g} . \mathrm{L}^{-1}$, diuron appeared significantly more embryotoxic than DCPMU and DCPU ( $<$ 0.001) (Fig. 2A), due to the high embryotoxic effect recorded for diuron at $0.5 \mu \mathrm{gL}^{-1}$ (nearly $55 \%$ of abnormalities). However, diuron showed a similar embryotoxic effect with the metabolites when considering a lower range of concentrations (0.002 to $\left.0.050 \mu \mathrm{g} \cdot \mathrm{L}^{-1}\right)$ ( $\mathrm{p}=0.3$ ) (Fig. 2B).

It is worth mentioning that variations among the different independent experiments were frequently observed during this study.

\subsubsection{Genotoxicity on oyster trochophore larvae}

In the case of diuron exposure, the main effect ANOVA showed a significant increase in tail DNA from $0.05 \mu \mathrm{g} . \mathrm{L}^{-1}(\mathrm{p}<0.001$ ) (Fig. 3) with no significant difference between the two experiments $(\mathrm{p}=0.61)$. The increase was of $8.9 \%$ at $0.05 \mu \mathrm{g} . \mathrm{L}^{-1}$ and $13.8 \%$ at 0.5 $\mu \mathrm{gL}^{-1}$ when compared to the solvent control. Exposure to 3,4-DCA also induced a genotoxic effect from the tested concentration of $0.05 \mu \mathrm{g} . \mathrm{L}^{-1}(+10.2 \%$ compared to the solvent control) ( $p<0.001$ ) (Fig. 3). In the case of DCPU ( $p=0.005)$, a significant increase in tail DNA was observed at the intermediate concentration of $0.05 \mu \mathrm{g} . \mathrm{L}^{-1}$ but not at 0.5 $\mu \mathrm{gL}^{-1}$ (Fig. 3). Concerning DCPMU, a genotoxic effect was only measured after exposure to $0.5 \mu \mathrm{g} . \mathrm{L}^{-1}(\mathrm{p}=0.001)$ with an increase in tail DNA of $14.2 \%$ compared to the solvent control (Fig. 3). Despite these slight individual differences in the genotoxic responses, the main effect ANOVA performed on all the data showed no significant difference between diuron and its metabolites ( $p=0.83$ ), all of them being responsible for a genotoxic effect from the concentration of $0.05 \mu g \mathrm{~L}^{-1}(\mathrm{p}<0.001)$.

\subsection{Implication of ROS production in diuron embryo- and genotoxicity}




\subsubsection{ROS production in trochophore larvae exposed to diuron}

Flow cytometric analysis revealed a steady concentration-dependent increase in ROS detection in trochophore larvae: from $92 \pm 13$ to $121 \pm 14$ and $197 \pm 13$ percent of FSW control after exposure to $0.002,0.05$ and $0.5 \mu \mathrm{g} . \mathrm{L}^{-1}$ of diuron, respectively (Fig.4). However, it became significantly different from the controls only after exposure to 0.5 $\mu \mathrm{g} . \mathrm{L}^{-1}$ of diuron $(\mathrm{p}<0.001)$. At this concentration, the fluorescent signal is similar to the one obtained following exposure to the positive control $\mathrm{H}_{2} \mathrm{O}_{2}(50 \mu \mathrm{M})$. It was significantly decreased by $71.1 \%$ in the presence of the ROS scavenger ascorbic acid (p < 0.001) (Fig. 4). Exposure to ascorbic acid only has no effect on ROS detection ( $p=0.07)$.

\subsubsection{Effect of co-exposure with ascorbic acid on the toxic responses}

Co-exposure of diuron, DCPMU or DCPU with ascorbic acid resulted in a significant decrease in the embryotoxic effect previously demonstrated for these molecules. In the case of diuron, ascorbic acid at a concentration of $25 \mu \mathrm{M}$ allowed a return to a basal level of frequency of abnormal D-larvae (from $46.2 \pm 3.4 \%$ abnormal D larvae at $0.5 \mu \mathrm{gL}-1$ to $22.0 \pm 2.6 \%(\mathrm{p}=0.1$ ) (Fig. 5). The same scenario was observed for DCPU and DCPMU following co-exposure with $10(\mathrm{p}=0.06)$ and $25 \mu \mathrm{M}(\mathrm{p}=0.08)$ of ascorbic acid, respectively (Fig. 5). The two independent experiments showed some differences in the results $(\mathrm{p}<0.01)$ with a batch of oyster genitors being more sensitive than the other one. When exposure to diuron was done in the presence of ascorbic acid, the genotoxic effect previously observed on trochophore larvae was cancelled and values were similar to those from the control $(\mathrm{p}=0.83)$ : $20.6 \pm 0.7 \%$ tail DNA versus $23.4 \pm 1.0 \%$ for diuron/ascorbic acid and DMSO control, respectively (Fig. 6). Exposure to ascorbic acid only did not trigger any DNA damage $(p>0.05)$. The two independent experiments did not show any differences $(\mathrm{p}=0.81)$.

\section{Discussion}

Diuron is both embryotoxic and genotoxic to oyster early life stages 
Diuron is classified as slightly toxic to aquatic invertebrates (Giacomazzi and Cochet, 2004). LC50s have been established for a number of species (e.g. Daphnia magna, Mysida sp.) and they are in the mg. $\mathrm{L}^{-1}$ range (0.16- $8.40 \mathrm{mg} . \mathrm{L}^{-1}$ ) (APVMA 2005). It seems to be more toxic to the Pacific oyster as adverse effects on adults were already reported following exposure to $1 \mu \mathrm{g} . \mathrm{L}^{-1}$ for 7 days (Buisson et al. 2008). In the study, authors exposed adult oysters to various concentrations of diuron and they observed atrophies of the digestive tubule epithelium and premature spawning in males.

In the present study, embryotoxic and genotoxic effects of diuron were demonstrated in C. gigas larvae in accordance with previous studies (Akcha et al. 2012; Mai et al. 2013; Barranger et al. 2014). Moreover, the first sign of embryotoxicity was observed at even lower level to what has already been published. Indeed, in this study, developmental toxicity was shown at a concentration as low as $0.01 \mu \mathrm{g} . \mathrm{L}^{-1}$ (different from the FSW control only) whereas it started from $0.05 \mu \mathrm{g} . \mathrm{L}^{-1}$ in the study of Akcha et al. (2012). This result is highly relevant from an environmental point of view, since diuron can be detected in coastal waters at concentrations up to $3.05 \mu \mathrm{g} . \mathrm{L}^{-1}$ (e.g. Okamura et al. 2003; Buisson et al. 2008; Munaron et al. 2012; Caquet et al. 2013).

Diuron appeared particularly toxic for the development of aquatic organisms such as different species of sea urchin (Kobayashi \& Okamura 2002; Manzo et al. 2006; Perina et al. 2011), the pink snapper P. auratus (Gagnon \& Rawson 2009), and the frog species $P$. regilla and X. laevis (Schuytema \& Nebeker 1998). Effective embryotoxic concentrations of diuron varied depending on the species. This is probably due to differences in the uptake and biotransformation abilities, which are the key factors determining the internal effective concentration of a toxic substance. Because of their filtering behaviour, oysters and bivalve molluscs are known to strongly accumulate pollutants in their tissues. Despite their lower ability to biotransform pollutants compared to vertebrates, they can bioactivate pollutants and express their toxicity. All this can explain why C. gigas appears especially sensitive to pollutant exposure, enforcing its role as a sentinel species in biomonitoring programs. It is worth mentioning that recently a parental exposure to diuron during gametogenesis was even shown to result in larvae abnormality in the offspring (Barranger et al., 2014). Herbicide pollution could therefore be of great environmental concern for its potential effect on the recruitment rate of this important exploited species. Such an effect could also result in direct damage to gametes that are 
directly released in water in the case of external reproduction. Exposure of oyster sperm to diuron resulted in a decrease in sperm quality in terms of both DNA integrity (Akcha et al., 2012) and fertilization ability (Mai et al., 2013).

The genotoxic effect of diuron has already been demonstrated in oyster. An increase in the level of DNA strand breaks was measured in the haemocytes after exposure of adults to $0.2-0.3 \mu \mathrm{g} . \mathrm{L}^{-1}$ for a short period of time (Barranger et al. 2014). In the present paper, we also demonstrated its genotoxicity at trochophore larvae stage following embryo exposure from $0.05 \mu \mathrm{g} . \mathrm{L}^{-1}$. In the present study, diuron genotoxicity is detected from the same concentration than that inducing a significant embryotoxic effect. The latter result appears different from the ones of Wessel et al. (2007) who investigated the toxicity of endosulfan, benzo(a)pyrene and $17 \alpha$-ethinyl estradiol (EE2) on oyster. Taking into account all their data, they showed a statistical correlation between genotoxicity and embryotoxicity; proposing genotoxicity as an earlier molecular event involved in the developmental abnormalities of chemical pollutants. To explain the effect of diuron on oyster development, other physiological mechanisms than genotoxicity could be explored. Girard et al. (1996) demonstrated that a disturbance in calcium homeostasis can be involved in early embryotoxicity in marine invertebrates. A dysfunction of calcium ion pumps was hypothesized in the embryotoxicity of estradiol (Roepke et al. 2005) and lead (Osman et al. 2007) in sea urchin and African catfish respectively. Zhou et al. (2011) specifically measured the activity of $\mathrm{Ca}^{2+}$ and $\mathrm{Na}^{2+}$ ion pumps in the case of an exposure to phthalate ester in abalone species. They found a positive correlation between the disruption of both ion pumps and the morphological effects that would results from the alteration in both ionic balance and osmoregulation.

\section{Diuron is more toxic than its studied metabolites}

Even though the metabolic profile of diuron has not been established yet in oyster, biotransformation is expected to occur due to the low BCF of diuron. Moreover, the presence of enzymes involved in the biotransformation of pollutants has already been demonstrated in oyster and several bivalves. A monoamine oxidase and a flavincontaining monooxygenase were characterized in oyster and their responses to xenobiotic exposure were analysed (Boutet et al. 2004). Moreover, the complete 
sequencing of the oyster genome allowed the discovery of numerous genes involved in response to environmental stress (Zhang et al. 2012).

In this study, diuron metabolites appeared less toxic than the parent compound considering embryotoxicity as toxic endpoint at concentrations lower than $0.05 \mu \mathrm{gL}^{-1}$. Embryotoxicity decreased with diuron metabolism as followed: diuron $\geq$ DCPMU $=$ DCPU $\geq 3,4$-DCA whereas genotoxicity was rather equivalent among the different chemical species.

Regarding embryotoxicity, biotransformation can thus constitute a true detoxication pathway by decreasing the toxicity of the parent compound. It is not always the case as biotransformation can also in some cases lead to the production of more reactive metabolites. As an example, the polycyclic aromatic hydrocarbon benzo[a]pyrene (BaP) undergoes biotranformation into the highly genotoxic compound 7,8-dihydrodiol-9,10epoxyde-BaP (BPDE) by oxidation catalyzed by cytochrome P450 enzymes in fish (Wessel et al 2007).

Comparing the toxicity of diuron to that of its metabolites is highly relevant. As a matter of fact, despite its rather strong persistence in water (Thomas et al., 2002), diuron can be abiotically and biotically degraded (Stasinakis et al. 2009; Salvestrini 2013; Zeng \& Arnold 2013). Therefore, oysters can be in contact with both diuron and its $\mathrm{N}$-demethylated metabolites in water bodies. Because oyster is also able to biotransform pollutants, it is worth studying the part of biotransformation in the toxicity of the herbicide in the aim to better understand the mechanisms involved and better assessed the chemical risk associated to the presence of the herbicide in the environment. Several studies have compared the toxicity of diuron and its metabolites. However, it has only be done so far using the standardized microtox test on both the bacteria Vibrio fischeri and the ciliate Tetrahymena pyriformis or a microalage-based bioassay. In the bacteria $V$. fisheri and the ciliate T. pyriformis, diuron and DCPMU were the most toxic molecules and DCPU the least or even not toxic (Tixier et al. 2000; Gatidou \& Thomaidis 2007). Using the same test, Bonnet et al. (2009) obtained different results with each diuron metabolite being more toxic than the parent compound. In the algal species P. subcapitata, C. closterium, P. tricornutum, Navicula sp. and N. pyriformis, Magnuson et al. (2010) and Neuwoehner et al. (2010) both established that diuron was more toxic than any of its metabolites for every species of microalgae they tested. The results of the present paper are the first ones to show the toxicity of diuron and its metabolites is on a filtering species. The results we 
obtained on the difference in toxicity between diuron and its metabolites are reliable thanks to the numerous independent experiments we conducted and the number of technical replicates we used. It is noteworthy that looking at different toxic endpoints may lead to different conclusions in comparing the toxicity of a substance and its metabolites, as the toxicity mechanisms involved could be different. In any way, our results are another hint that the toxicity of diuron and its metabolites are extremely species- and assayspecific as has been concluded previously (Bellas et al. 2005).

3,4-DCA did not show any embryotoxic potential to oyster larval stages and was only slightly genotoxic under the tested range of concentrations (low $\mu$ g. $\mathrm{L}^{-1}$ ). 3,4dichloroaniline is a classical final product of the biotransformation of phenylurea herbicides in animals (Tixier et al. 2001). It is classified as very toxic to aquatic life with long-lasting effects following the Global Harmonized System of Classification and Labelling of Chemicals (GHS). DCA is a class 1 acute and chronic toxicant to aquatic life following the Classification, Labelling, Packaging (CLP) Directive (2008/1272/EC). 3,4DCA is also a classical positive control in fish embryotoxicity assay. However, toxic and embryotoxic effects reported in fish for 3,4-DCA are observed at concentrations nearly one order of magnitude higher than those tested in the present study. For fish embryotoxicity assay, EC50 values are in the range of mg.L-1 (Zhu et al. 2013; Saeed et al. 2015), e.g., around 6 mg. $\mathrm{L}^{-1}$ in the zebrafish (Braunbeck \& Lammer 2006). In crucian carp, Li et al. (2003) showed that 3,4-DCA triggered necrosis and degenerative lesions in liver that could be due to oxidative stress and lipid peroxidation from the concentration of 0.2 mg.L-1. The effective toxic concentration of 3,4-DCA is also high in other species such as $D$. magna. Using the immobilization test, a higher toxicity was shown for diuron metabolites compared to the parent compound, 3,4-DCA being the most toxic one with an EC50 value of $226 \mathrm{mg} . \mathrm{L}^{-1}$ (Neuwoehner et al. 2010). It is therefore not surprising to not have observed signs of embryotoxicity after 3,4-DCA exposure in oyster for the concentrations tested in the present study.

Biotransformation of diuron in oyster is consequently expected to reduce the toxicity of diuron but at different extent with different endpoints. This could be explained by difference in the mechanisms involved in different species. Moreover, other byproducts should be considered, as free radicals that can also be generated during biotransformation of the parent compound. 


\section{Diuron toxicity involves ROS production}

ROS production is believed to be one of the major mechanism underlying target and nontarget toxicity of many classes of pesticides (Slaninova et al. 2009). It has been widely illustrated for the herbicide paraquat, a non-selective contact herbicide of the dipyridinyl class. This herbicide interferes with intracellular electron transfer systems in plants and animals leading to the generation of the superoxide anion which in turn leads to the formation of more toxic oxygen reactive species such as hydrogen peroxide and hydroxyl radical (Winston \& DiGiulio 1991). ROS interact with unsaturated lipids of membranes resulting in the destruction of cellular compounds leading to necrotic and apoptotic death (Bus and Gibson 1984; Kappus 1986). The mode of action of the herbicide diuron in plants is based on the release of ROS, leading to oxidative damage to pigments, proteins, nucleic acids and lipids (Geoffroy et al. 2002). In non-target species, ROS have been suspected to be responsible for diuron toxicity as well. Diuron toxicity in the urinary bladder of rats had been shown to be mediated by ROS production, with a significant over-expression of genes involved in oxidative stress (Ihlaseh et al. 2011). In oyster, Bouilly et al. (2007) showed an increase in ROS production in the haemocytes following a 4-week exposure to 0.3 and $3 \mu \mathrm{g} . \mathrm{L}^{-1}$ of diuron. Decrease in the activity of the antioxidant enzyme superoxide dismutase was also reported in oyster after exposure to $1 \mu \mathrm{g} \cdot \mathrm{L}^{-1}$ diuron for 6 and $24 \mathrm{~h}$ (Luna-Acosta et al. 2012). Moreover, the genotoxic effect of diuron demonstrated by the comet assay in oyster (Akcha et al, 2012; Barranger et al. 2014, this study) is another indirect clue that diuron toxicity could be mediated by oxidative stress. Indeed, the comet assay allows the detection of DNA strand breaks that are known to result mainly from the attack on the DNA by ROS.

Measurement of ROS production inside an organism can only be done by comparing induced peak values with background level since natural biological processes generate ROS. It is more challenging to measure ROS during embryogenesis and in early larval stages that are characterized by strong fluctuating cellular activities and ROS production (Hutchinson et al 1998; Mohammed 2013). Moreover, ROS have by definition very short lifetime. These are the reasons why classical ways of investigating oxidative stress in organisms are to measure its effects on enzyme activities or macromolecules such as catalase, glutathione-S-transferase, lipid peroxidation or DNA adducts (Lushchak 2011). To get a more "real-time" picture of ROS production inside cells, different techniques are 
available such as flow cytometry that is the most widely used technique thanks to the development of ROS-sensitive fluorescent probes. However, such studies are usually performed on single cells from multi-cellular organisms or on unicellular organisms. In the present study, co-exposure with known anti-oxidant compounds followed by flow cytometry analysis allowed us to highlight the involvement of ROS in the toxicity of diuron and its metabolites. L-Ascorbic acid is a form of vitamin $\mathrm{C}$ that can provide as its reduced ion ascorbate two electrons to terminate chain reactions initiated by free radicals before their reaction with biological molecules (Suntres, 2002; Evans \& Halliwell, 2012). Moreover, ascorbic acid is also able to regenerate other antioxidant molecules such as $\alpha$ tocopherol, glutathione (GSH) and $\beta$-carotene (Evans \& Halliwell 2012). $N$-acetylcysteine is first metabolised in the organisms to form molecules able to promote detoxification, scavenge free radicals and stimulate GSH synthesis (Zafarullah et al. 2003). The efficiency of these molecules to limit the toxicity of chemical pollutants has already been mentioned in the bibliography. In the study from Vismara et al. (2001), the embryotoxicity of paraquat on the frog Xenopus laevis was significantly reduced when the animals were coexposed with ascorbic acid. It is worth mentioning that ascorbic acid on its own can induce embryotoxicity in oyster when present at concentrations above $100 \mu \mathrm{M}$ (results not shown). Such an effect has already been reported at high doses (500 mg/day in human leucocytes) and it has been explained by the ability of ascorbic acid to accelerate the generation of hydroxyl radical by quickening the redox cycling of free metal ions (Evans and Halliwell 2012).

\section{Conclusions}

In the present study, the embryotoxicity and genotoxicity of diuron and its DCPMU and DCPU metabolites were shown in early life stages of the Pacific oyster at environmentally relevant concentrations. Herbicide pollution could therefore be of great environmental concern for its potential effect on the recruitment rate of this important exploited species. The final metabolite of diuron, 3,4 DCA, was only slightly genotoxic to oyster trochophore larvae. It appeared to be devoid of embryotoxic effect for the tested concentrations. These concentrations were one order of magnitude lower than those used as positive controls in fish embryotoxicity test. Regarding our results, biotransformation can constitute a detoxication pathway in oyster by decreasing the embryotoxicity of the parent compound. 
Diuron biotransformation is expected to occur in oyster due to the low BCF values calculated for this organism. To bring direct evidence of the ability of the oyster to biotransform diuron, LC-MS/MS analysis are currently in progress in order to detect and quantify the different diuron metabolites produced by oyster during its life cycle. Because it is a species with external reproduction, it is of particular interest to study and compare also the ability of gametes to biotransform pesticides due to their direct release in the surrounding waters.

Oxidative stress is involved in both toxic endpoints measured in the oyster. ROS overproduction is commonly observed in the case of pollutant exposure and is a well known mediator of toxicity. ROS can directly react with the DNA being responsible of DNA damage. Concerning their effects on oyster development, further research is needed to identify the mechanisms involved. The impact of herbicide exposure on calcium homeostasis is also a point that need to be investigated in parallel.

\section{Acknowledgments}

This work was funded by Ifremer and the French National Agency for Research (ANRCESA-01601). The authors would like to thank Juliette Desfrançois-Noel, Nadège Marec and Laurine Haro from the Cytocell platform for their help and availability regarding the cytometric analysis.

\section{References}

Abass, K. et al., 2007. Characterization of Diuron N -Demethylation by Mammalian Hepatic Microsomes and cDNA-Expressed Human Cytochrome P450 Enzymes. Drug Metabolism and Disposition, 35(9), pp.1634-1641.

Akcha, F., Spagnol, C. \& Rouxel, J., 2012. Genotoxicity of diuron and glyphosate in oyster spermatozoa and embryos. Aquatic Toxicology, 106, pp.104-113.

APVMA, 2005. The Reconsideration of Approvals of the Active Constituent Diuron , Registrations of Products containing Diuron and their Associated Labels. , 1(July), pp.1-52.

Awadalla, E.A., 2012. Efficacy of vitamin C against liver and kidney damage induced by paraquat toxicity. Experimental and Toxicologic Pathology, 64(5), pp.431-434.

Barranger, A. et al., 2015. Parental exposure to environmental concentrations of diuron leads to aneuploidy in embryos of the Pacific oyster, as evidenced by fluorescent in 
situ hybridization. Aquatic Toxicology, 159, pp.36-43.

Barranger, A. et al., 2014. Study of genetic damage in the Japanese oyster induced by an environmentally-relevant exposure to diuron: Evidence of vertical transmission of DNA damage. Aquatic Toxicology, 146, pp.93-104.

Bellas, J. et al., 2005. Toxicity of organic compounds to marine invertebrate embryos and larvae: A comparison between the sea urchin embryogenesis bioassay and alternative test species. Ecotoxicology, 14(3), pp.337-353.

Blahová, J. et al., 2013. Oxidative stress responses in zebrafish Danio rerio after subchronic exposure to atrazine. Food and Chemical Toxicology, 61, pp.82-85.

Bonnet, J.-L. et al., 2009. Effect of 1-butyl-3-methylimidazolium tetrafluoroborate on the wheat (Triticum aestivum L.) seedlings. Environmental toxicology, 24(3), pp.296303.

Bouilly, K. et al., 2007. Impact of Diuron on Aneuploidy and Hemocyte Parameters in Pacific Oyster, Crassostrea gigas. Archives of Environmental Contamination and Toxicology, 52(1), pp.58-63.

Boutet, I., Tanguy, A. \& Moraga, D., 2004. Molecular identification and expression of two non-P450 enzymes, monoamine oxidase A and flavin-containing monooxygenase 2, involved in phase I of xenobiotic biotransformation in the Pacific oyster, Crassostrea gigas. Biochimica et biophysica acta, 1679(1), pp.29-36.

Braunbeck, T. \& Lammer, E., 2006. Fish embryo toxicity assays. Available at: www.oecd.org/chemicalsafety/testing/36817242.pdf.

Buisson, S. et al., 2008. Level of contamination and impact of pesticides in cupped oyster, Crassostrea gigas, reared in a shellfish production area in Normandy (France). Journal of Environmental Science and Health, Part B : Pesticides, Food Contaminants, and Agricultural Wastes, 43, pp.655-664.

Bus, J.S. \& Gibson, J.E., 1984. Paraquat : Model for Oxidant-Initiated Toxicity. Environmental Health Perspectives, 55, pp.37-46.

Caquet, T. et al., 2013. Risk assessment of herbicides and booster biocides along estuarine continuums in the Bay of Vilaine area (Brittany, France). Environmental Science and Pollution Research, 20(May 2015), pp.651-666.

Evans, P. \& Halliwell, B., 2012. Micronutrients : oxidant / antioxidant status Micronutrients : oxidant / antioxidant status. British Journal of Nutrition.

Gagnaire, B. et al., 2007. Combination of a pesticide exposure and a bacterial challenge: in vivo effects on immune response of Pacific oyster, Crassostrea gigas (Thunberg). Aquatic toxicology (Amsterdam, Netherlands), 84(1), pp.92-102.

Gagnon, M.M. \& Rawson, C.A., 2009. Diuron increases spinal deformity in early-life-stage 
pink snapper Pagrus auratus. Marine pollution bulletin, 58(7), pp.1083-5.

Gatidou, G. \& Thomaidis, N.S., 2007. Evaluation of single and joint toxic effects of two antifouling biocides, their main metabolites and copper using phytoplankton bioassays. Aquatic Toxicology, 85, pp.184-191.

Geoffroy, L. et al., 2002. Effect of oxyfluorfen and diuron alone and in mixture on antioxidative enzymes of Scenedesmus obliquus. Pesticide Biochemistry and Physiology, 72, pp.178-185.

Giacomazzi, S. \& Cochet, N., 2004. Environmental impact of diuron transformation: a review. Chemosphere, 56(11), pp.1021-32.

Girard, J., Pesando, D. \& Payan, P., 1996. Calcium Homeostasis and Early Embryotoxicity in Marine Invertebrates. Comparative Biochemistry and Physiology - C Toxicology and Pharmacology, 113(2), pp.169-175.

Glusczak, L. et al., 2006. Effect of glyphosate herbicide on acetylcholinesterase activity and metabolic and hematological parameters in piava (Leporinus obtusidens). Ecotoxicology and Environmental Safety, 65, pp.237-241.

Griboff, J. et al., 2014. Oxidative stress response induced by atrazine in Palaemonetes argentinus: The protective effect of vitamin E. Ecotoxicology and environmental safety, 108C, pp.1-8.

Hutchinson, T.H., Solbé, J. \& Kloepper-Sams, P.J., 1998. Analysis of the ECETOC Aquatic Toxicity (EAT) database. III - Comparative toxicity of chemical substances to different life stages of aquatic organisms. Chemosphere, 36(1), pp.129-142.

Ihlaseh, S.M. et al., 2011. Transcriptional profile of diuron-induced toxicity on the urinary bladder of male wistar rats to inform mode of action. Toxicological Sciences, 122(2), pp.330-338.

Jacquet, F., Butault, J.P. \& Guichard, L., 2011. An economic analysis of the possibility of reducing pesticides in French field crops. Ecological Economics, 70(9), pp.16381648.

Kappus, H., 1986. Overview of enzyme systems involved in bio-reduction of drugs and in redox cycling. Biochem.Pharmacol., 35(1), pp.1-6.

King, J., Alexander, F. \& Brodie, J., 2013. Regulation of pesticides in Australia: The Great Barrier Reef as a case study for evaluating effectiveness. Agriculture, Ecosystems \& Environment, 180, pp.54-67.

Kobayashi, N. \& Okamura, H., 2002. Effects of new antifouling compounds on the development of sea urchin. Marine Pollution Bulletin, 44, pp.748-751.

Li, W. et al., 2003. 3,4-dichloroaniline-induced oxidative stress in liver of crucian carp (Carassius auratus). Ecotoxicology and environmental safety, 56, pp.251-255. 
Loos, R. et al., 2013. Analysis of polar organic contaminants in surface water of the northern Adriatic Sea by solid-phase extraction followed by ultrahigh-pressure liquid chromatography - QTRAP @ MS using a hybrid triple-quadrupole linear ion trap instrument. , pp.5875-5885.

Lourencetti, C., Demarchi, M. \& Ribeiro, M., 2008. Determination of sugar cane herbicides in soil and soil treated with sugar cane vinasse by solid-phase extraction and HPLCUV. Talanta, 77(2), pp.701-709.

Luna-Acosta, A. et al., 2012. Detection of early effects of a single herbicide (diuron) and a mix of herbicides and pharmaceuticals (diuron, isoproturon, ibuprofen) on immunological parameters of Pacific oyster (Crassostrea gigas) spat. Chemosphere, 87(11), pp.1335-40.

Lushchak, V.I., 2011. Environmentally induced oxidative stress in aquatic animals. Aquatic Toxicology, 101(1), pp.13-30.

Mai, H. et al., 2013. Environmental concentrations of irgarol, diuron and S-metolachlor induce deleterious effects on gametes and embryos of the Pacific oyster, Crassostrea gigas. Marine Environmental Research, 89, pp.1-8.

Manzo, S., Buono, S. \& Cremisini, C., 2006. Toxic effects of Irgarol and Diuron on sea urchin Paracentrotus lividus early development, fertilization, and offspring quality. Archives of Environmental Contamination and Toxicology, 51, pp.61-68.

Mohammed, A., 2013. Why are Early Life Stages of Aquatic Organisms more Sensitive to Toxicants than Adults? New Insights into Toxicity and Drug Testing, pp.49-62.

Moncada, A., 2004. Environmental Fate of Diuron. Ground Water. Available at: http://www.cdpr.ca.gov/docs/emon/pubs/fatememo/diuron.pdf.

Munaron, D. et al., 2012. Estuarine, Coastal and Shelf Science Pharmaceuticals , alkylphenols and pesticides in Mediterranean coastal waters : Results from a pilot survey using passive samplers. Estuarine, Coastal and Shelf Science, 114, pp.82-92.

Neuwoehner, J. et al., 2010. QSAR-analysis and mixture toxicity as diagnostic tools: Influence of degradation on the toxicity and mode of action of diuron in algae and daphnids. Aquatic Toxicology, 97(1), pp.58-67.

Ngigi, A. et al., 2011. Biodegradation of phenylurea herbicide diuron by microorganisms from long-term-treated sugarcane-cultivated soils in Kenya. Toxicological and Environmental Chemistry, 93(8), pp.1623-1635.

Osman, A.G.M. et al., 2007. Lead Induced Malformations in Embryos of the African Catfish Clarias gariepinus ( Burchell , 1822 ). Environmental toxicology, 22, pp.375389.

Pätzold, S. \& Brümmer, G.W., 2003. Influence of microbial activity and soil moisture on 
herbicide immobilization in soils. - Journal of Plant Nutrition and Soil Science, 166(3), pp.336-344.

Perina, F.C. et al., 2011. Comparative toxicity of antifouling compounds on the development of sea urchin. Ecotoxicology, 20, pp.1870-1880.

Quiniou, F. et al., 2007. Marine water quality assessment using transplanted oyster larvae. Environment International, 33, pp.27-33.

Renault, T., 2011. Effects of pesticides on marine bivalves: what do we know and what do we need to know? Pesticides in the Modern World - Risks and Benefits, pp.227240.

Roepke, T.A., Snyder, M.J. \& Cherr, G.N., 2005. Estradiol and endocrine disrupting compounds adversely affect development of sea urchin embryos at environmentally relevant concentrations. Aquatic Toxicology, 71, pp.155-173.

Saeed, S. et al., 2015. Arabian killifish (Aphanius dispar) embryos: a model organism for the risk assessment of the Arabian Gulf coastal waters. Environmental Toxicology and Chemistry, 34(12), pp.2898-2905.

Salvestrini, S., 2013. Diuron herbicide degradation catalyzed by low molecular weight humic acid-like compounds. Environmental Chemistry Letters, 11, pp.359-363.

Samain, J.F. et al., 2007. Genetically based resistance to summer mortality in the Pacific oyster (Crassostrea gigas) and its relationship with physiological, immunological characteristics and infection processes. Aquaculture, 268, pp.227-243.

Schuytema, G.S. \& Nebeker, A. V, 1998. Comparative toxicity of diuron on survival and growth of Pacific treefrog, bullfrog, red-legged frog, and African clawed frog embryos and tadpoles. Arch Environ Contam Toxicol, 34(4), pp.370-376.

Slaninova, A. et al., 2009. A review: Oxidative stress in fish induced by pesticides. Neuroendocrinology Letters, 30(Suppl 1), pp.2-12.

Sørensen, S.R. et al., 2003. Microbial degradation of isoproturon and related phenylurea herbicides in and below agricultural fields. FEMS Microbiology Ecology, 45(1), pp.111.

Stasinakis, A.S. et al., 2009. Diuron biodegradation in activated sludge batch reactors under aerobic and anoxic conditions. Water Research, 43(5), pp.1471-1479.

Suntres, Z.E., 2002. Role of antioxidants in paraquat toxicity. Toxicology, 180, pp.65-77.

Thomas, K. V., McHugh, M. \& Waldock, M., 2002. Antifouling paint booster biocides in UK coastal waters: Inputs, occurrence and environmental fate. Science of the Total Environment, 293, pp.117-127.

Tixier, C. et al., 2001. Degradation products of a phenylurea herbicide, diuron: Synthesis, 
ecotoxicity, and biotransformation. Environmental Toxicology and Chemistry, 20(7), pp.1381-1389.

Tixier, C. et al., 2000. Fungal biodegradation of a phenylurea herbicide, diuron: Structure and toxicity of metabolites. Pest Management Science, 56(August 1999), pp.455462.

Vethaak, A.D. et al., 2015. Integrated indicator framework and methodology for monitoring and assessment of hazardous substances and their effects in the marine environment. , pp.1-10.

Vismara, C., Vailati, G. \& Bacchetta, R., 2001. Reduction in paraquat embryotoxicity by ascorbic acid in Xenopus laevis. Aquatic Toxicology, 51, pp.293-303.

Wessel, N. et al., 2007. Investigating the relationship between embryotoxic and genotoxic effects of benzo[a]pyrene, 17??-ethinylestradiol and endosulfan on Crassostrea gigas embryos. Aquatic Toxicology, 85, pp.133-142.

Winston, G.W. \& DiGiulio, R.T., 1991. Prooxidant and antioxidant mechanisms in aquatic organisms. Aquatic Toxicology, 19, pp.137-161.

Zafarullah, M. et al., 2003. Cellular and Molecular Life Sciences Molecular mechanisms of $\mathrm{N}$-acetylcysteine actions. , 60, pp.6-20.

Zeng, T. \& Arnold, W. a., 2013. Pesticide photolysis in prairie potholes: Probing photosensitized processes. Environmental Science and Technology, 47(13), pp.6735-6745.

Zhang, G. et al., 2012. The oyster genome reveals stress adaptation and complexity of shell formation. Nature, 490(7418), pp.49-54.

Zhou, J., Cai, Z.-H. \& Xing, K.-Z., 2011. Potential mechanisms of phthalate ester embryotoxicity in the abalone Haliotis diversicolor supertexta. Environmental pollution (Barking, Essex : 1987), 159(5), pp.1114-1122.

Zhu, B. et al., 2013. Developmental toxicity of 3 , 4-dichloroaniline on rare minnow ( Gobiocypris rarus ) embryos and larvae. Chemosphere, 90(3), pp.1132-1139. 


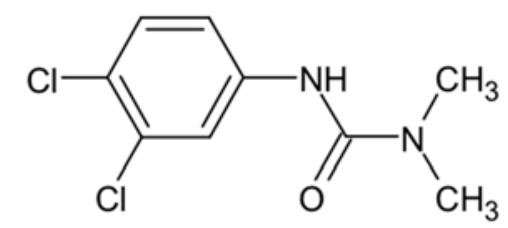

a.

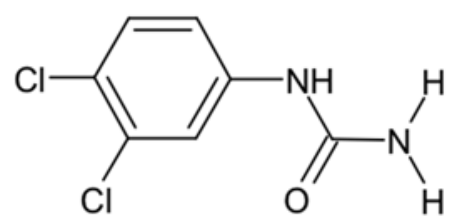

C.

Fig. 1. Molecular structures of diuron (a.), DCPMU (b.), DCPU (c.) and 3,4-DCA (d.). Figures were drawn using ACD/ChemSketch.

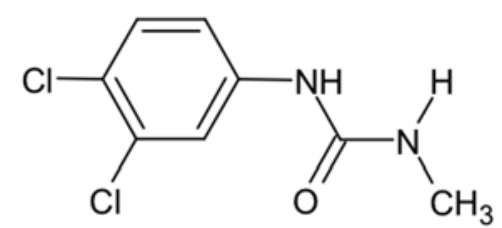

b.

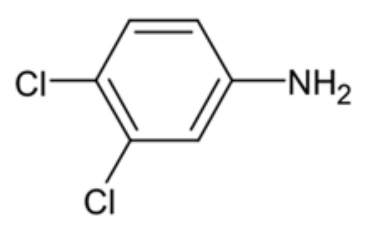

d. 
Mean; Wiskers: Meant0.95 Conf. Interval

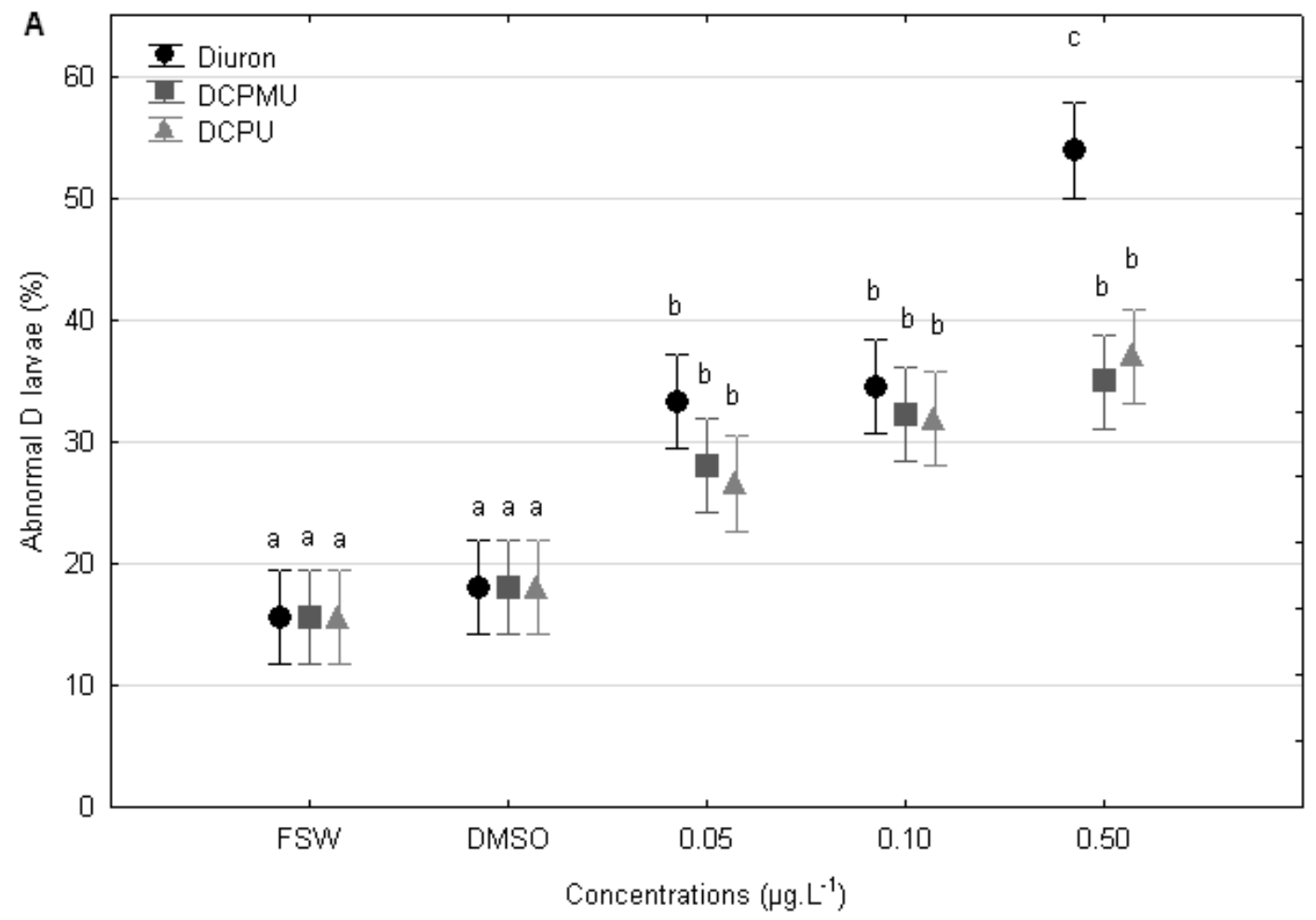

B

Mean; Wiskers: Meant0.95 Conf. Interval

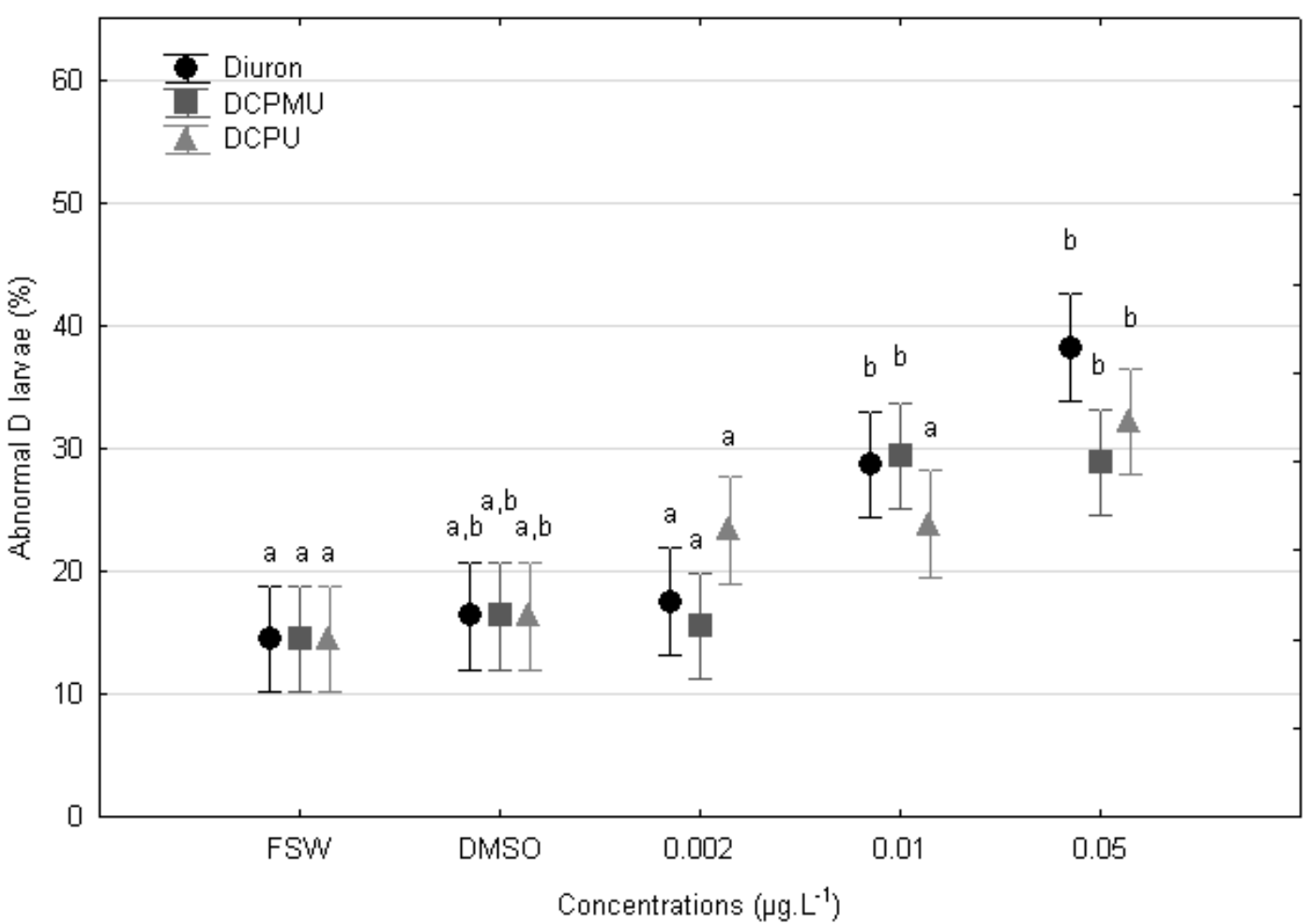

Fig. 2. Comparative embryotoxicity of diuron, DCPMU and DCPU on oyster D-larvae after a 24h exposure to the two tested ranges of common concentrations: 0.050 to $0.50 \mu \mathrm{g}$.L-1 (A) and 0.002 to $0.050 \mu \mathrm{g}$. $\mathrm{L}^{-1}$ (B). Main effect ANOVA, $N=9, \mathrm{p}<0.001$, followed by Tukey Post Hoc test. Data that do not show same letters differ significantly $(\mathrm{p}<0.05)$. 


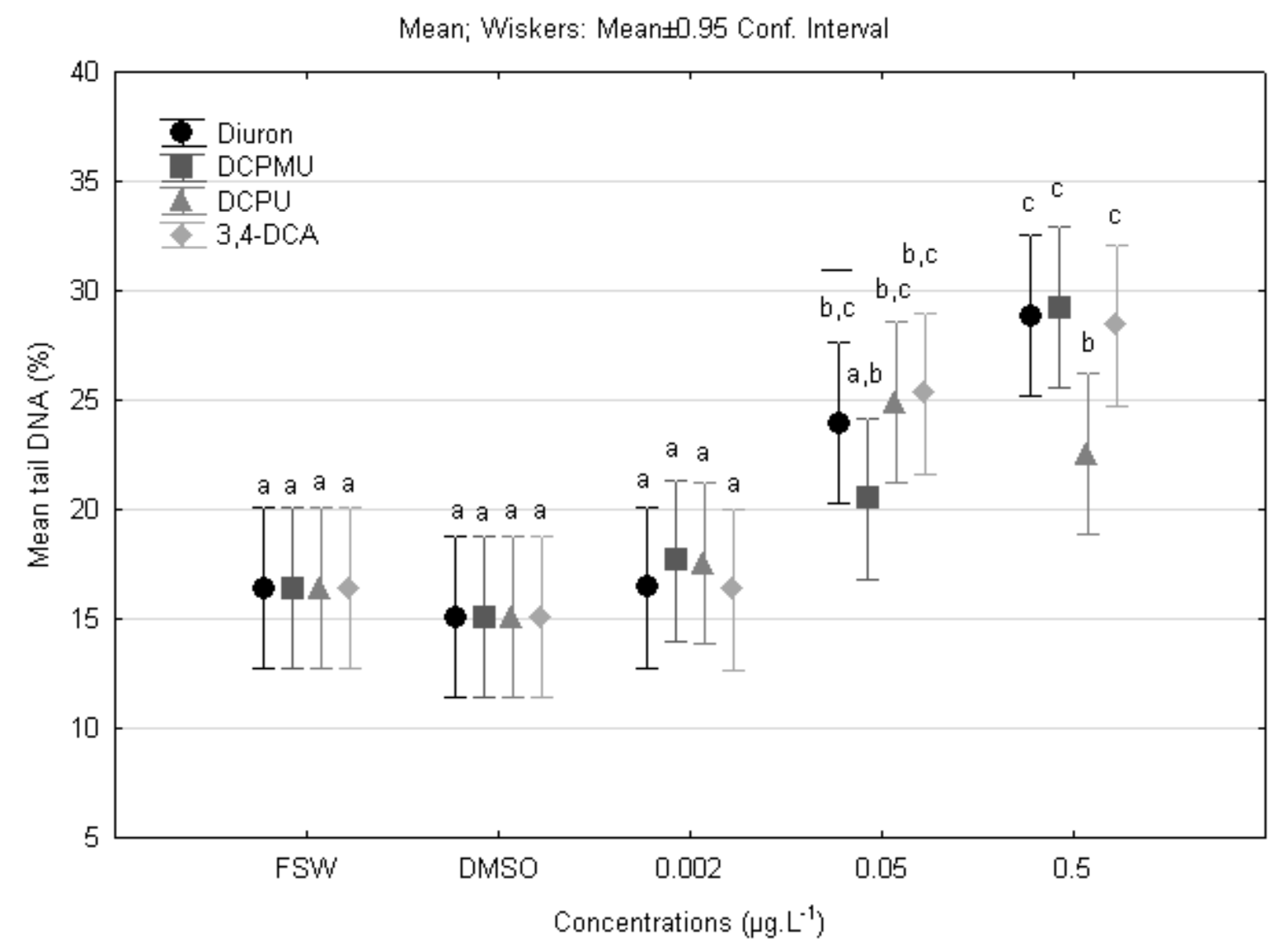

Fig. 3. Comparative genotoxicity of diuron, DCPMU, DCPU and 3,4-DCA on oyster trochophore larvae after $6 \mathrm{~h}$ of exposure. Main effect ANOVA, N =6, p < 0.001, followed by Tukey's multiple comparison Post Hoc test. Data that do not show same letters differ significantly $(p<0.05)$. 


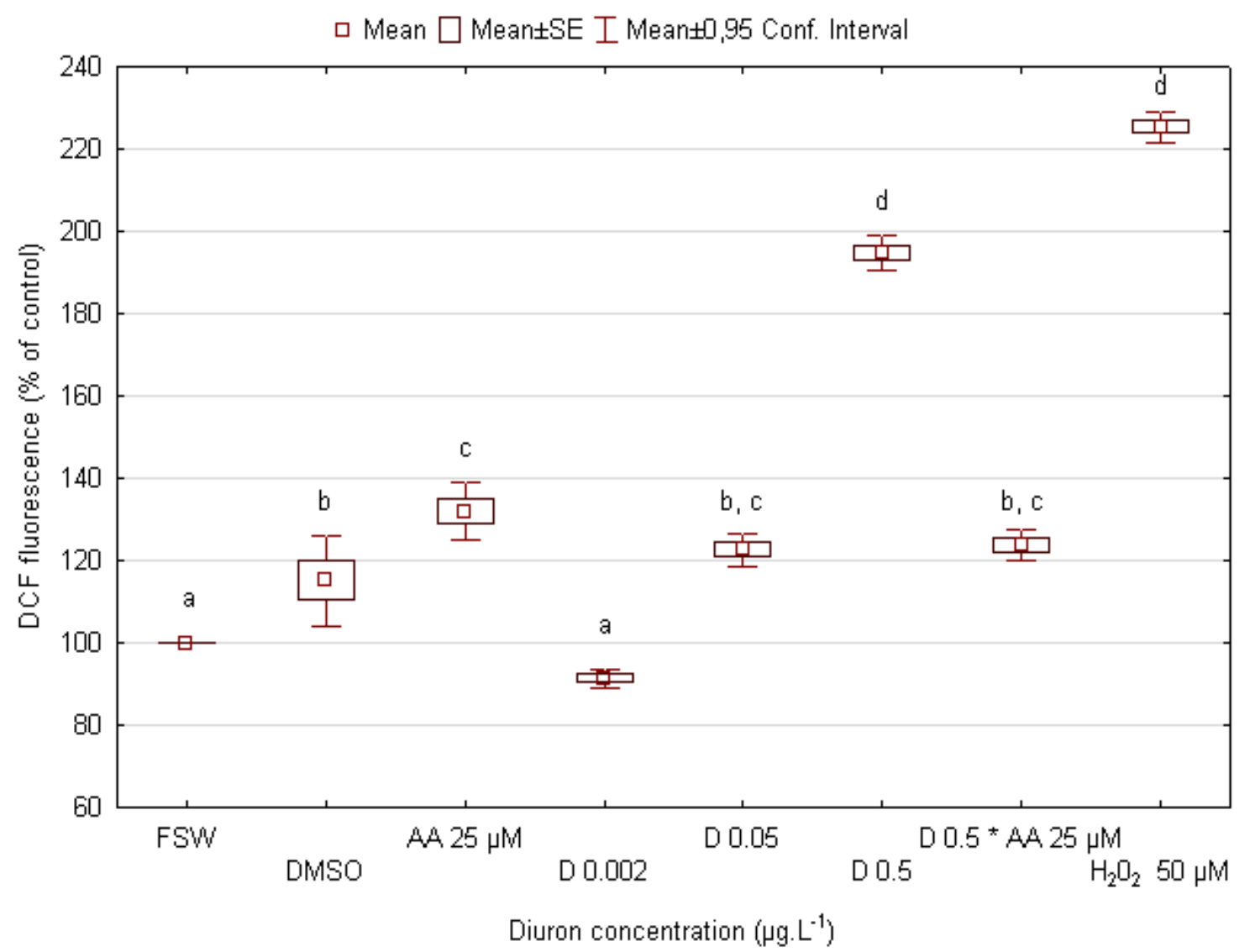

Fig. 4. Effect of different concentrations of diuron without or supplemented with ascorbic acid on ROS production in trochophore larvae after $6 \mathrm{~h}$ of exposure. Main-effect ANOVA, $\mathrm{N}=9, \mathrm{p}<0.001$, followed by Tukey's multiple comparison Post Hoc test. Data that do not show same letters differ significantly $(p<0.05)$. 


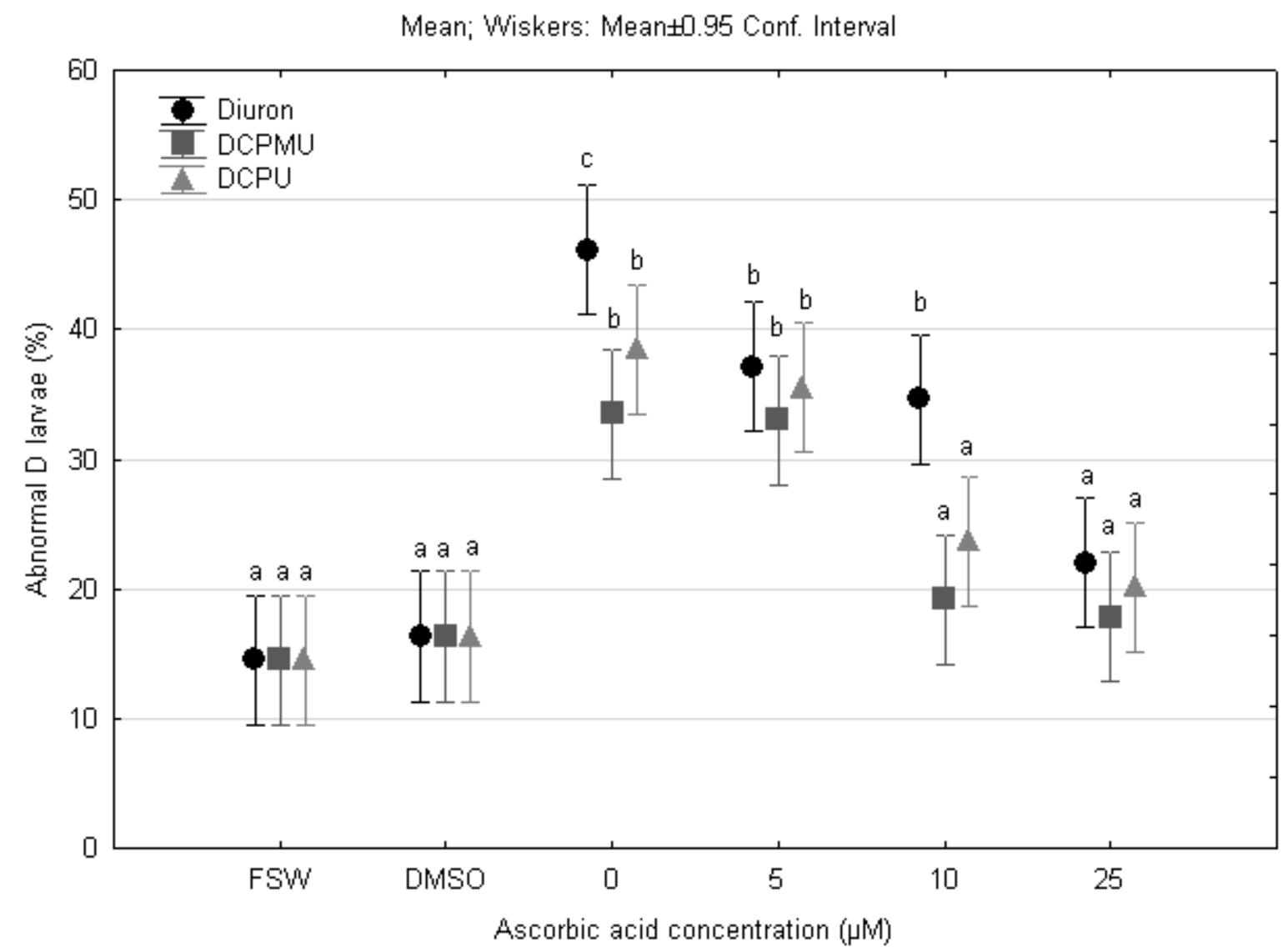

Fig. 5. Comparative effects of ascorbic acid on diuron, DCPMU and DCPU -induced embryotoxicity in oyster D-larvae after $24 \mathrm{~h}$ of exposure. Main-effect ANOVA, $\mathrm{N}=6, \mathrm{p}<0.001$ followed by Tukey's multiple comparison Post Hoc-test. Data that do not show same letters differ significantly $(\mathrm{p}<0.05)$. 


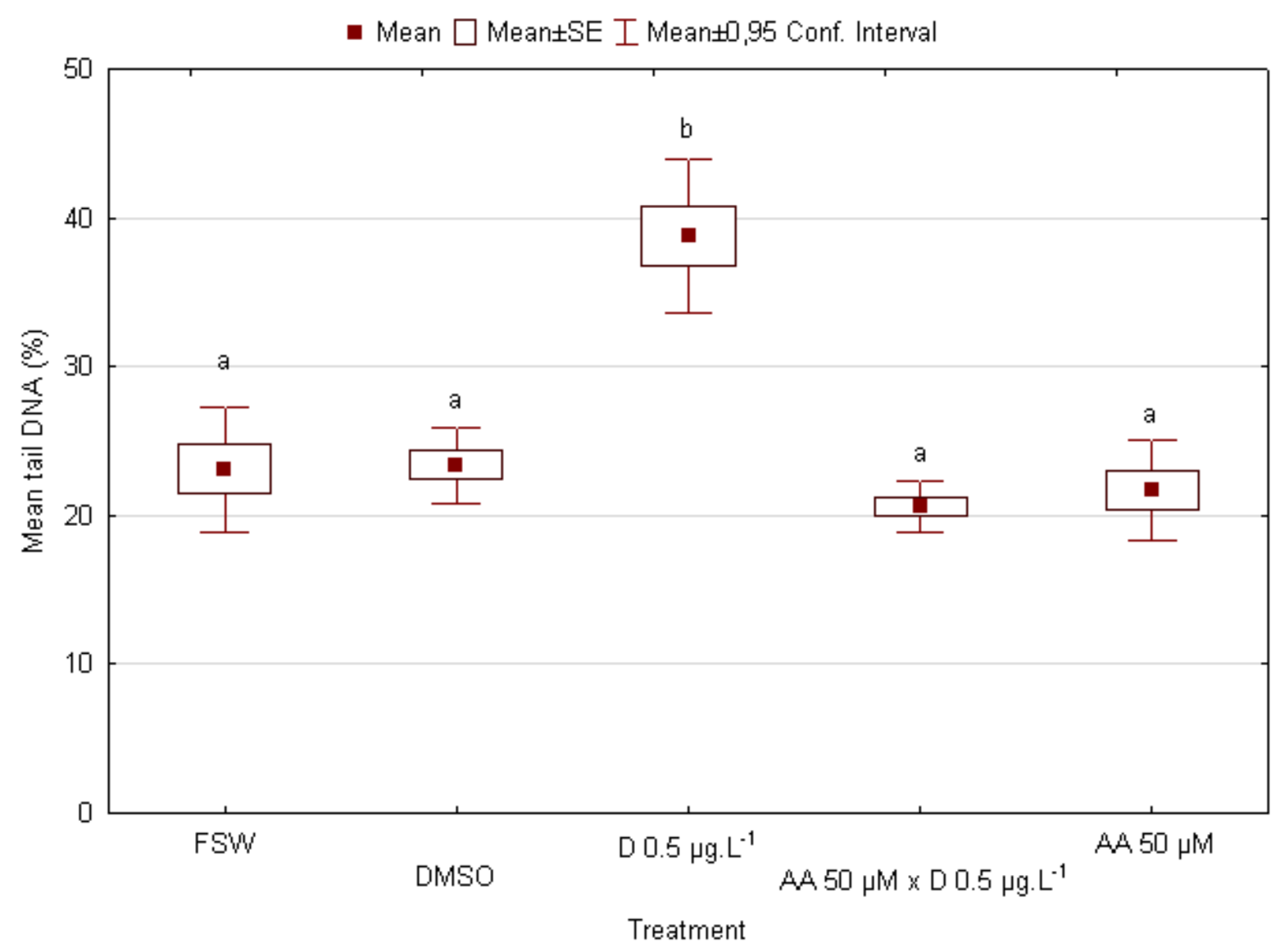

Fig. 6. Effect of ascorbic acid (AA) on diuron (D)-induced genotoxicity in oyster trochophore larvae after 6 $\mathrm{h}$ of exposure. Main-effect ANOVA, $\mathrm{N}=6, \mathrm{p}<0.001$, followed by Tukey's multiple comparison Post Hoc test. Data that do not show same letters differ significantly $(\mathrm{p}<0.05)$. 
Table 1 - Experimental design of the two different sets of experiments investigating the embryotoxicity induced by diuron and its DCPMU, DCPU, 3,4-DCA metabolites. The number of time the bioassay was independently repeated is given in brackets.

\begin{tabular}{|c|c|c|}
\hline & \multicolumn{2}{|c|}{ Tested concentrations ( $\mu$ g. $\left.L^{-1}\right)$} \\
\hline & $1^{\text {st }}$ set of experiments & $2^{\text {nd }}$ set of experiments \\
\hline Diuron & $0.05-0.1-0.5(2)$ & $\begin{array}{l}0.002-0.01-0.05-0.5 \\
(2)\end{array}$ \\
\hline DCPMU & $\begin{array}{l}0.01-0.05-0.1-0.5-2.5 \\
(3)\end{array}$ & $\begin{array}{l}0.002-0.01-0.05-0.5 \\
(2)\end{array}$ \\
\hline DCPU & $\begin{array}{l}0.01-0.05-0.1-0.5-2.5 \\
(3)\end{array}$ & $\begin{array}{l}0.002-0.01-0.05-0.5 \\
(2)\end{array}$ \\
\hline 3,4-DCA & $\begin{array}{l}0.01-0.05-0.1-0.5-2.5 \\
(2)\end{array}$ & Not tested \\
\hline
\end{tabular}

